\section{Achieve bonded brackets without stress or mess}

Bonding brackets to teeth using adhesive can be a tricky business. It's easy to make slight mistakes and to spend time readjusting brackets so that they are in the optimal position.

But what if there was a way to achieve perfectly bonded brackets without the stress or the mess?

The APC Flash-Free Adhesive Coated Appliance System from 3M Oral Care is your key to beautifully bonded brackets.

Unlike traditional adhesive application methods, it forms a smooth meniscus of adhesive when placed, preventing the need for excess clear up and clumps of dried adhesive where bacteria and plaque can gather.

For more information, call 08458734066 or visit www.3m.co.uk/apcff. $3 \mathrm{M}$ representatives remain contactable by phone or via video conferencing $3 \mathrm{M}$ and $\mathrm{APC}$ are trademarks of the $3 \mathrm{M}$ Company.

\section{Refer your complex or urgent case}

If you are dealing with a complex or urgent case, such as a patient with a severely atrophic maxilla, consider referring your patient to the Centre for Oral-Maxillofacial and Dental Implant Reconstruction, an International ZAGA centre based in Manchester.

Led by Professor Cemal Ucer - Specialist Oral Surgeon - the clinic utilises the Zygoma Anatomy-Guided Approach (ZAGA), a technique pioneered by Carlos Aparicio. This has been designed to minimise the risk of complications previously experienced with conventional zygomatic implants for the very best results every time.

The experienced and friendly team will put your patient at ease, while keeping them safe with strict adherence to hygiene and safety protocols. Make contact today to find out more about your local ZAGA Centre. Contact Professor Ucer at ice@ucer.uk or Mel Hay at mel@mdic.co. Call 01612371842.

\section{Learn how to lead through the new normal}

After the most challenging 12 months, the dental landscape, like most others, has shifted - how do we navigate a way forward?

The next British Dental Conference and Dentistry Show seeks to answer this very question with a unique two-day programme of lectures and interactive sessions, and a prestigious panel of nationally and internationally-renowned speakers.

Nowhere else can those running or working within a dental practice in the UK find the same calibre of practical insights to take on the biggest issues, and find ways to help them lead their practice through change - all completely free of charge.

Save the date to learn ways to adapt to the 'new normal' and thrive in a post vaccine world.

Don't miss the most important British Dental Conference and Dentistry Show to date!

The next British Dental Conference and Dentistry Show will be held on Friday 13 and Saturday 14 May 2022, Birmingham NEC, co-located with DTS.

For more information, visit www.thedentistryshow.co.uk, call 02073485270 or email dentistry@closerstillmedia.com.

\section{Effective relief from hypersensitivity}

ProphyCare HAp is a new generation of prophy pastes with a unique composition including hydroxyapatite that effectively will block the open dentine tubules on an exposed dentine surface. The result is a barrier that will provide the patient with instant relief from hypersensitivity.

ProphyCare HAp is used for both

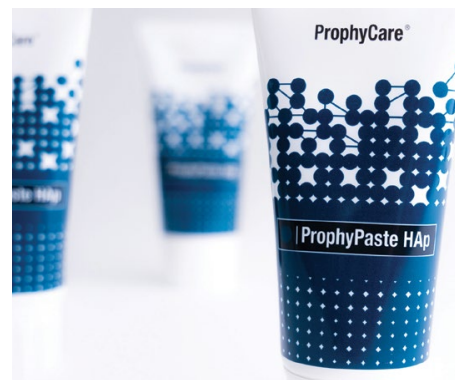
stain removal and final polishing.

It offers effective stain removal properties at the beginning of the treatment, then the abrasive effect gradually reduces, giving the paste its final polishing properties at the end of the treatment. Using the same paste for stain removal and final polishing offers decreased treatment time. It is fluoride and paraben free and studies have shown that products containing hydroxyapatite show better remineralising properties than traditional fluoride products. ProphyCare HAp's mild mint taste and appealing texture is pleasant for patients of all ages and does not splatter, liquify or separate and is easy to rinse-off.

For more information visit www.directadental.com.

\section{One step to success}

For one-step cementation choose SoloCem, from COLTENE.

In three shades, SoloCem offers reliable values and adhesion to dentine, enamel and other material.

Further benefits lie in its time-saving application. The automix syringe and ready-to-use mixing tips support efficiency, and the simplicity reduces the risk of error.

Other features:

- Self-adhesive and dual cure

- Fluorescent

- An intraoral processing time of approximately one minute

- Easy removal of excess, after light curing.

And now SoloCem combined with COLTENE's One Coat 7 Universal bond can have enhanced bonding. Ideal for those techniques and dentists who prefer a belt and braces approach.

To upgrade your dentistry, call COLTENE.

For more on COLTENE, visit www.coltene.com, email info.uk@ coltene.com or call 08002545115.

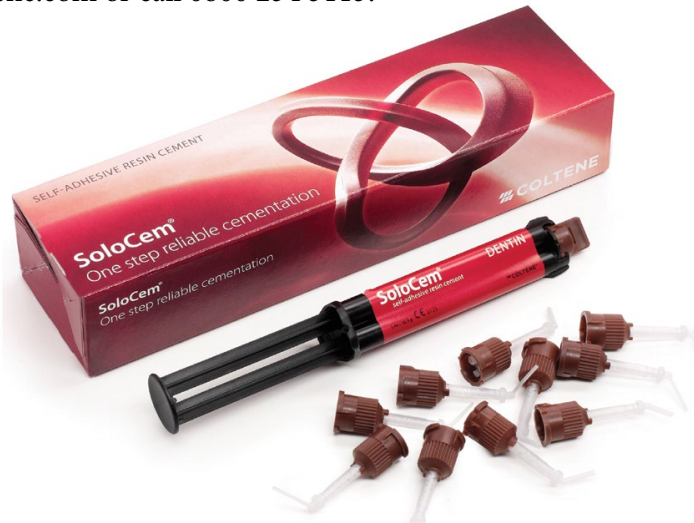

